\title{
UNA RUPTURA EN LA ORDENACIÓN DEL SABER DE LAS ENCICLOPEDIAS MEDIEVALES. EL INVENCIONARIO (1474) DE ALFONSO DE TOLEDO
}

\author{
José Luis Fuertes Herreros \\ Universidad de Salamanca
}

\section{RESUMEN}

Situada la enciclopedia del saber de Alfonso de Toledo dentro de dicha tradición enciclopédica, se estudia el Invencionario, 1474, destacando la ruptura que practica con respecto al orden medieval y sus enciclopedias. Ruptura que anuncia una nueva ordenación de los saberes y que manifiesta un cambio de época: el tránsito de la Edad Media al Renacimiento.

\begin{abstract}
If Alfonso de Toledo's encyclopedia of knowledge is situated within the encyclopedic tradition, the Invencionario, 1474, is studied, highlighting the break it made with respect to the medieval order and its encyclopedias, a break which announced a new ordering of knowledge and which manifests a change of age: the transition from the Middle Ages to the Renaissance.
\end{abstract}

\section{INTRODUCCIÓN}

1. De entre la rica biblioteca de la Universidad de Salamanca he seleccionado para este trabajo un manuscrito de excepcional importancia que en sus días de gloria fue familiar en diversos escriptorios y bibliotecas, y muy conocido y leído en distintas cortes y universidades.

En Salamanca, un ejemplar perteneció al Colegio Mayor de San Bartolomé, fundado en 1401, y otro, de copista distinto, al Mayor de Cuenca, que en 1500 fundaba Diego Ramírez de Villaescusa, obispo de Cuenca, bajo la advocación de Santiago el Zebedeo.'

I Ambos manuscritos se hallan en la Biblioteca General de la Universidad de Salamanca. El del Colegio de San Bartolomé tiene la signatura ms. 2406, papel, y consta de 170 folios, 305 x $220 \mathrm{~mm}$. El de Cuenca, ms. 2421, papel, 119 folios, con caja de escritura a dos columnas, 310 × $220 \mathrm{~mm}$. Sigo el de Cuenca e indico también columna $a \circ b$. 
Su autor se llamaba Alfonso de Toledo, se decía bachiller en decretos, había titulado, certeramente, su obra Invencionario, 1474, y la había dedicado al Arzobispo de Toledo, Alonso (Alfonso) Carrillo, ${ }^{2}$ generoso con los estudiantes de la Universidad de Salamanca, entre los cuales, favorecido, se había encontrado el dicho Diego Ramírez de Villaescusa.

Tras el esplendor del Invencionario, ocaso y latencias en el tiempo, ${ }^{3}$ avivando su luz, trataré, ahora, de desvelar algunos de sus significados más notables, viéndolo formar parte de aquella tradición tan fecunda como es la de las enciclopedias del saber, a la que por derecho propio pertenece. Tradición que, arrancando del mundo antiguo, atravesaba el mundo medieval, llegaba a Alfonso de Toledo, para proseguir a través de líneas y metamorfosis distintas en la modernidad. Tradición y enciclopedia la de Alfonso de Toledo que recoge y ordena los distintos saberes e invenciones (inventos) en esos finales del XV, cuando parecía que se clausuraba o fragmentaba el mundo medieval y en pluralidad de tensiones se asistía al nacimiento del mundo moderno.

2. Las enciclopedias en la historia del pensamiento y de la cultura habían ido plasmando y condensando el desarrollo de la filosofía, de la ciencia y de las concepciones religiosas, tratando de ordenar el saber desde un punto de unificación, que había variado según el contexto hubiera sido griego o romano, judío, árabe o cristiano.

La tradición enciclopédica, que se había recibido del mundo antiguo, comienza a tener un tono teológico conforme se va produciendo la cristianización del pensamiento y de la cultura en Europa, y va a ir reflejando en cada momento la arquitectura del saber desde la que se ordena la realidad, así como el puesto y el valor que adquiere en dicha ordenación la fe, las artes, las ciencias, el propio hombre y las realidades mundanas. Las enciclopedias que aquí van a ir surgiendo, desde el principio unificador que las envuelve, marcan una línea clara de continuidad y de perfeccionamiento en la elaboración y preeminencia de los saberes teológicos y de las realidades divinas sobre los saberes, filosóficos, sobre las artes, liberales, serviles o mecánicas, y sobre las realidades mundanas. Corriente y tradición de pensamiento que se va conformando y pasa, entre otros, por San Agustín, Boecio, Marciano Capella, Casiodoro, san Isidoro, Ricardo de San Víctor, Alano de Lille, Bartolomé de Glanville (Bartholomeus Anglicus), santo Tomás, Ramón Llull, Alfonso de la Torre o Rodrigo Sánchez de Arévalo, en un intento de acercarnos a Alfonso de Toledo. ${ }^{+}$

Esta preminencia de la teología sobre todos los otros saberes se fundamentaba en el concepto de ciencia que los autores medievales tenían, vinculado a una opción previa de fe. Éstos entendían por ciencia un conocimiento cierto y necesario. ${ }^{5}$ La teología y la filosofía

2 Fol. 7/a.

3 Beaujouan, G. Manuscrits scientifiques médiévaux de l'Université de Salamanca et de ses «Colegios Mayores», Bordeaux, 1962, 36, 153-54.

4 Crawford, J. P., «The seven liberal Arts in the 'Vision Delectable'», The Romanic Review, 4 (1913), 58-75. Trevisa, J., introd. a la ed. De rerum proprietatibus, Oxford, 1975. Muñoz Delgado, V., «Las artes mecánicas y liberales en Rodrigo Sánchez de Arévalo», Studia Zamorensia, 4 (1983), 35-61. Fuertes Herreros, J. L., Sabiduría y artes en el Renacimiento, Salamanca, 1984.

5 Muñoz Delgado, 38. 
constituían principalmente la ciencia. La teología aparecía como doctrina fundada en la revelación divina y la filosofía, como campo de investigación de la razón. De esa fe, y mayor garantía, surgía la excelencia de la teología, reclamando el servicio de la filosofía y de las artes e iluminando a ambas.

Las enciclopedias medievales desempeñarían una función teológico-ordenadora y reflejaban la ordenación de un mundo cristiano y la posibilidad de configurarlo desde una vertiente teórico-práctica en ese practicar a lo divino el obsequilum rationale, que pregonara San Pablo en Rom. 12,1 y 2 Cor. 10,5 como actitud propia del cristiano. Tal ocurrirá, como señalaré más adelante, en Alfonso de la Torre, que en su Visión deley'table de la philosofía et de las otras sciençias, 1430-40, nos sitúa en un doble plano de realidad y de saberes: el mundano y el divino; y en una supeditación de las artes, de la filosofía y de la ciencia a la teología y a la revelación, que en la alegoría de ascenso al cielo y encuentro con la divinidad se nos ofrece la plena verdad, tanto desde una vertiente teórica como práctica.

Sin embargo, Alfonso de Toledo en el Invencionario va a romper con esa fundamentación y ordenación del saber, con esa jerarquía y rango que se establecía entre los saberes y entre las artes, liberales o mecánicas, o entre la ciencia y las demás artes. y va a introducir una ordenación distinta, que va a suponer una consideración nueva en torno a la finalidades de la filosofía, una revalorización de la ciencia, de las artes mecánicas y de las liberales; un nuevo modo de ordenar los saberes, no ya hacia finalidades trascendentes cuanto hacia el hombre, hacia el mejoramiento de la vida; una reflexión nueva en torno al hombre como artifex, en torno a la razón como poder de inventio, en torno a las invenciones o inventos como manifestaciones del poder del hombre, que mediante dichas invenciones se procura solícitamente el bienestar y el mejoramiento.

El mundo en el Invencionario aparece como el señorío del hombre, dañado desde el pecado original, pero que la razón del propio hombre trata de mejorar y de hacer confortable mediante las distintas invenciones que en el tiempo histórico ha ido produciendo. Y es este hombre el que inventa el modo de relacionarse y aplazer a Dios según las diversas invenciones que ha producido en las distintas leyes, ley de natura, escritura y gracia, en las cuales se divide la historia, pues Dios aparece como alejado del hombre y del mundo, y desde el cual resulta dificil fundamentar un orden en el saber.

Con los elementos propios de ese mundo cambiente del siglo $\mathrm{XV}$, que en germen contenía muchas de las claves para comprender el surgir del desarrollo de la modernidad, Alfonso de Toledo construirá su enciclopedia y practicará su ruptura con la ordenación del saber medieval.

\section{ALFONSO DE TOLEDO Y SU RELATO DEL GÉNESIS, 1-3, EN EL INVENCIONARIO}

El punto de partida en la construcción de esta enciclopedia va a ser la lectura que Alfonso de Toledo hace del relato de la creación del Génesis, capítulos 1-3. ¿Y por qué el 
relato del génesis? Porque el relato del Génesis, 1-3, sobre la creación del universo y del mundo, del hombre, sobre el paraíso, la tentación, caída y primera promesa de redención, constituye uno de los núcleos sobre el que se refleja y modula buena parte de las relaciones entre la filosofía y la teología, o entre la ciencia y la teología. La interpretación que se hace de dicho relato nos descubre la actitud con que se ha leído dicho pasaja y el tipo de soluciones que se darán, entre otros, a temas tales como el fin último del hombre, sentido de la historia, relaciones entre Dios y hombre, preeminencia o no de lo religioso... Dicho relato creador está presente, bien implícita bien explícitamente, en toda la tradición patrístico-medieval y atraviesa la modernidad, apareciendo recogido en autores tales como Descartes, Hobbes, Locke, Voltaire o Kant. Las distintas modulaciones, o fes, que experimenta dicho pasaje acaban señalándonos el papel asignado a la razón, a la filosofía, a la ciencia, a la teología y el distinto modo de ordenar la realidad.

Por otra parte, el relato y apelación a Génesis, 1-3, sirve para fijar y desplegar el tiempo de la historia, y comenzar el gran relato de uan historia escatológico-salvífica: Dios/ eternidad, creación, tiempo histórico, historia como historia de salvación, Dios/eternidad. Dicho relato ordena la realidad y establece puntos de seguridad y estructuras de orden. El hombre, cualquiera que sea, desde las coordenadas de Génesis, 1-3, puede saber su posición y orientarse en el tiempo de la historia, le sirve para establecer un probable inicio de la historia humana.

Alfonso de Toledo, desde su clara intención de escribir una historia de las invenciones, expresada en la dedicatoria al arzobispo de Toledo, no podía escapar a este recurso del Génesis, 1-3, pues tenía necesidad de fijar un probable inicio de la historia para establecer cuál podía haber sido la situación original y para, desde ahí, iniciar la historia de las invenciones, indicando sus causas y motivos, ${ }^{6}$ y dando cuenta de las invenciones tanto temporales como espirituales.

Esta fijación de un inicio probablemente de la historia en un comienzo culturalmente aceptado y fechado, era la que posibilitaba la división de la historia, como tiempo finito, en edades, tal como enseñaba S. Isidoro, o en leyes, tal como arrancando del mismo S. Pablo y de la tradición patrística aparecía en la tradición medieval y llegaba, también, a Alfonso de Toledo. ${ }^{7}$

Esta reconstrucción histórica, que arrancaba de una situación original y primigenia, es la que posibilitaba marcar la andadura de esa historia y las metas que desde una situación de presente parecían haberse conseguido.

Esta historia de las invenciones de Alfonso de Toledo está contruida, además, desde una perspectiva universal, no parece circunscribirse a ningún ámbito geográfico concreto, ni estar ceñida a un determinado campo del saber. El Invencionario es la propia historia de la

6 Fol. 7/a: «E el tratado es assy llamado, conuiene a saber, ynvençionario, porque en él se fallarán los primeros ynuentores de las cosas assy temporales como espirituales e los motiuos e causas de las ynuençiones».

7 San Isidoro, Etimologías, 2 vols., BAC, Madrid, 1982-83, V, 38-39, pág. 551-65; VI, 17, 16, pág. 16. Rom. 4, 15; 7, 9; 8, 2, 13. 
razón del hombre, que practica el ars inventiva a través de los distintos tiempos, hombres y esfuerzos; es y ha sido para Alfonso de Toledo una tarea colectiva: «E por quanto estos yngenios e argumentos non fueron ynventados por uno, mas por muchos, ni en un tiempo, mas en muchos, ni por una conssideración, más por muchas e diverssas». ${ }^{8}$ No hay ninguna mira localista, ni de exaltación concreta, tal como en estos momentos podía aparecer en las crónicas. Es más bien una exposición que cubre la distancia que nos separa de aquella situación original de la que se logró salir, que llega hasta su presente y que señala el compromiso de tareas futuras.

Imagina Alfonso de Toledo que en esa situación primera el hombre fue reducido a una condición «más miserable» que «los brutos animales» después de «la transgresión del padre primero», ya que ésta «grand misseria engendró en la condición humanal». ${ }^{9}$

Esta situación de miseria en que quedó el hombre conlleva para Alfonso de Toledo dos consecuencias importantes. La primera, que «veyendosse de tan grand nesçesidat constrenido» se vio impulsado «mediante el benefiçio de la razón» a investigar «muchoss engenios e argumentos» por donde «a la sustentaçión de la temporal vida pudiesse rreparar»; y la segunda, por donde pudiese «a Dios aplazer».

Así el hombre se vio forzado a echar sobre sus hombros una doble empresa prometeica, la de socorrer a sus necesidades, y la de intentar, también, por sus propios medios e ingenio, «aplazer a Dios». En este relato de Alfonso de Toledo no hay promesa de redención, ni de reconciliación mesiánica, ni se pretende engarzar la historia con una historia de la salvación desde un plan salvífico que se iría realizando en el tiempo histórico. Entre Dios y el hombre parece haberse roto ese vínculo relacional. Dios queda confinado a su propia divinidad y es el hombre el que inicia su propia andadura e historia de salvación, tanto temporal como espiritual.

La historia, y la historia de las invenciones, queda así recortada a ese nivel de inmanencia y linealidad, en donde la razón, el esfuerzo, sudor y lazería del hombre se van a ver forzados a iniciar y desarrollar el ars inventiva por la propia necesidad. Y así el tiempo histórico es tiempo de invenciones.

Es desde esta perspectiva desde donde el hombre, o Alfonso de Toledo, parece romper con la tradición del obsequium rationale para situarse en la perspectiva de la scientia rationalis tal como se irá constituyendo en la modernidad. Hay una apuesta en favor de la razón y de la acción del hombre, y un construir la historia desde la propia autonomía de éste. $\mathrm{Y}$ es ésta la que rompe con la ordenación tradicional del saber medieval. 


\section{DEL OBSEQUIUM RATIONALE A LAS ENCICLOPEDIAS}

El hecho de que Alfonso de Toledo haya presentado como proemio del Invencionario la narración del Génesis, que he indicado, tiene una importancia fundamental.

Este proemio se me aparece como una de las claves para comprender el espíritu que anima la empresa de Alfonso de Toledo, y la ruptura que propugna, a pesar de las concesiones epocales que a través de su obra podamos descubrir.

La lectura medival del Génesis, 1-3, con su culminación en la promesa de salvación realizada en Cristo y en la Iglesia, desde esa perspectiva de nueva fe, nueva ley y nueva vida que ya señalaba S. Pablo, es la que condujo a ir articulando esa actitud vital e intelectual frente a lo religioso cristiano, que se condensaba en la fórmula paulina del obsequium rationale y del intellectum in obsequium Christi. ${ }^{10}$ Esta actitud marcaba nítidamente desde sus comienzos la superioridad de la fe sobre la razón, de la teología sobre la filosofía; y desde la arquitectura del saber que derivaba, señalaba la sumisión de la razón frente a la fe, quedando la razón confinada a unos límites de frágiles seguridades mundanas, que habían de ser contemplados desde una mirada de fe.

Esta actitud y secreto, el obsequium rationale, es, en definitiva, el que merecerá la salvación y otorgará la sabiduría. Esta apertura a la fe, a mirar de modo preeminente las cosas de Dios, o desde esa instalación, ya dada, en la sabiduría, es la que servirá para señalar la diferencia entre sabiduría y ciencia, entre sabiduría y saberes. Tanto la sabiduría como la ciencia serán dones de Dios, " y lo que a un cristiano le salvará, no será una u otra, sino el obsequium que el hombre puede prestar a la verdad. Sería la empresa en que se había empeñado desde un primer momento la patrística y la filosofía medieval, la de construir un orden intelectual, o político e intelectual, que de suyo praticara el obsequitum. Entre estas construcciones aparecían las enciclopedias.

No con ánimo de efectuar una historia de este recorrido, sino con el proposito de establecer algunos puntos de referencia, que jalonan esta fina elaboración, y que van a estar presentes en las enciclopedias que llegan hasta Alfonso de Toledo, señalo algunas notas de esta trayectoria.

\section{A) San Agustín}

San Agustín, desde una perspectiva cristiana, es el que establecerá un doble orden de realidades y de conocimiento. Las cosas y las verdades temporales se ordenan a las eternas, la ciencia a la sabiduría, y ésta a Dios. La ciencia tendrá por objeto el conocimiento racional de las cosas temporales y mudables del mundo sensible. Y la sabiduría se ocupará del conocimiento intelectual de las realidades y verdades eternas, inmutables, del mundo

10 Rom, 12, 1: «[...] Deo placentem rationabile obsequium vestrum». 2 Cor, 10,5: «[...] et in captivitatem redigentes omnem intellectum in obsequium Christi».

11 Rom, 2,20. San Próspero de Tiro, De vocatione omnium gentium: «quod scientia et intellectus dona sint Dei», PL. 51, 1, 24. 
suprasensible o inteligible: «Si, por consiguiente, ésta es de sabiduría y ciencia, es una distinción recta; para que pertenezca a la sabiduría debe ser conocimiento intelectual de las cosas divinas; por contra, a la ciencia, conocimiento racional de las cosas temporales; cual se deba anteponer o posponer a quién, no es difícil de juzgar». ${ }^{12}$

El estudio de las cosas divinas le pertenece a la sabiduría y el de las cosas humanas, temporales, finitas, el de las realidades del mundo inferior, le pertenece a la ciencia. Por ello, la ciencia debe subordinarse a la sabiduría, a Dios que es la verdad: "Qué se puede decir que es la sabiduría sino que es sabiduría de Dios? Recibimos, también, de la divina autoridad de Dios que el hijo de Dios no es otra cosa que la sabiduría de Dios. ¿Qué pensáis que es la sabiduría sino la verdad? También esto ha sido dicho: Yo soy la verdad». ${ }^{13}$

El obsequium rationale es un presupuesto obligado desde la óptica de San Agustín. La ciencia humana tiene un valor propedéutico para la sabiduría divina. Es un precioso auxiliar para ayudar a comprender el sentido de la Escritura, en que se contiene la palabra de Dios. Pero no debe cultivarse por sí misma, sino sólo en cuanto que contribuye a elevarnos a la sabiduría: «El mismo [Cristo] para nosotros, a través de la fe, estará contenido en las cosas temporales; él mismo muestra la verdad de las cosas eternas. Por él vamos a parar a él mismo, por la ciencia nos dirigimos a la sabiduría». ${ }^{1+} \mathrm{O}$ desde esa fórmula más conocida y quizá más condensada: «Cree para que comprendas». ${ }^{15}$

\section{B) La carta Ab Aegiptiis de Gregorio IX}

Esa posibilidad, que se ofrecía, de vivir desde las obras del Espíritu Santo, o bien desde la scientia o desde la sapientia en base al obsequium rationale, históricamente se va ir materializando, al menos como doctrina oficial de la Iglesia, en una visión y articulación de la realidad desde la sabiduría, como aspiración y concreción de una ciencia ideal.

Dejando otros intentos anteriores, el siglo XIII va a ser decisivo en estos cometidos y logros. A modo, también, de ejemplificación, indico cómo la carta Ab Aegiptiis de Gregorio IX a los teólogos parisienses, de 1228, alude a la necesidad de huir de las novedades que se querían introducir en la Universidad de París (Aristóteles y las consecuencias de autonomía que para la razón conllevaba), y de hacer que el estudio de la teología discurriera por los cauces tradicionales, esto es, vía obsequium rationale.

Dice la carta, entre otras cosas: «Tocados de dolor de corazón intimamente[...] porque, según se ha comunicado a nuestros oídos, algunos entre vosotros, hinchados como un odre por el espíritu de vanidad, pugnan por traspasar con profana vanidad los términos puestos por los Padres[...]. Pues siendo su deber exponer la teología según aprobadas tradiciones de los Santos y destruir, no por armas carnales, sino poderosas en Dios, y reducir cautivo todo entendimiento en obsequio de Cristo (2 Cor. 10,4s); ellos, llevados de doctrinas varias

\footnotetext{
12 De Trinitate, XII, 15, 25, PL. 42.

13 De beata vita, IV, 34, PL. 32.

14 De Trinitate, XIII, 19, 24, PL. 42.

15 Serm, 43,7, PL. 38.
} 
y peregrinas $(H e b r .13,9)[\ldots]$ obligan a la reina a servir a su esclava[...]. Evita las profanas novedades de palabras y las opiniones de la ciencia de falso nombre, que por apetecerla algunos han caído de la fe (1 Tim. 6,20s)[...]». ${ }^{16}$

Creo que este texto recoge admirablemente el sentir de la Iglesia en estos comienzos del siglo XIII y señala la posición y dirección institucional que había tomado.

\section{C) Santo Tomás}

En estos contextos del XIII, y dentro de ese esfuerzo de ordenación y síntesis, se halla la obra de Sto. Tomás. Sólo quiero hacer un brevísimo comentario a algunos aspectos de la I q.1 de la Summa Theologiae, al hilo de lo que voy señalando.

En esta cuestión primera, Sto. Tomás se preguntará: «Si es necesario que haya una doctrina distinta de las ciencias filosóficas». ${ }^{17}$ Desde esa instalación y opción de fe, siempre presente en él, responderá a esta pregunta apelando al plan salvífico de Dios, a la ordenación del hombre a Dios y a la necesidad de la revelación divina para que se diera a conocer al hombre dicho plan. Con esta lectura, como telón de fondo, del Gén. 103, la filosofía aparecerá como scientia rationalis y la teología como scientia divina.

La filosofía y las disciplinas filosóficas son aquellas «que son inventadas según la razón humana», «las cuales son investigadas por las razón humana», «tratan en cuanto son cognoscibles según la luz natural de la razón»; y la teología, por su parte, es la ciencia «divinamente inspirada», y con unos contenidos «que superan a la razón humana», «que como son más altos que el conocimiento del hombre, no deben ser inquiridos por éste, son sin embargo, por Dios revelados, debiendo ser contemplados desde la fe», y de la cual «depende toda la salvación del hombre, la cual está en Dios». ${ }^{18}$ Sto. Tomás retomará, también, los conocidos planteamientos de san Agustín en De Trinitate, XII: «La sabiduría es conocimiento de las cosas divinas», ${ }^{19} \mathrm{e}$ indicará cómo Dios es el sujeto de esta ciencia: «Dios es el sujeto de esta ciencia». ${ }^{20}$

A partir de q. 2 de la Summa Theologiae Sto. Tomás se esforzará en construir in crescendo esa admirable armonía entre fe y razón.

¿Qué actitud debería tomar como propia el cristiano, si esto es así, si la teología es la reina y la filosofía la esclava?, tal como enseñaba el papa Gregorio IX, y tal como insiste, ahora, Sto. Tomás, trayendo la autoridad de los Proverbios, 9,3: «envió a sus siervas a llamar desde la fortaleza». ${ }^{21}$ En efecto, no queda otra que la ya señalada por San Pablo, recogida por Gregorio IX, y ahora, nuevamente, recordada por Sto. Tomás: «Y por esto dice

16 Denifle, H., Chatelain, E., Chartularium Universitatis Parisiensis, París, 1889-97. I, 59. Denzinger, E., El magisterio de la Iglesia, Herder, Barcelona, 1963, 442-43.

17 S. Th. I q. 1, a. 1.

$18 \mathrm{Ib}$.

$19 \quad l b$. a. 6.

$20 \quad$ Ib. a. 7.

21 Ib. a. 5. 
el Apostol, II Cor. 10,5, "reduciendo a cautividad todo pensamiento en obsequio de Cristo"». ${ }^{22}$

D) Conclusión

Desde S. Pablo, pasando por la patrística y por la Edad Media se van dando todo un conjunto de elaboraciones teóricas, que han ido tendiendo a hacer patente la preeminencia de lo religioso sobre lo profano, de la fe sobre la razón, de la teología sobre la filosofía, de la sabiduría sobre los saberes y las ciencias.

Esta preeminencia y excelencia, por otra parte, tendía a crear un orden institucional eclesial y político - La monarquía de Sto.Tomás será un exponente claro, así como la tradición de tratados de príncipes-, que desde diversas instancias de poder será propagado, defendido y divulgado a través de diferentes cauces y métodos pedagógicos. Las enciclopedias del saber será uno de ellos, así como los tratados de consolación, o los de príncipes, entre otros.

El siglo XIII, sobre todo desde el significado que la obra de Sto. Tomás adquiere en este contexto, representa la culminación de esa pulida elaboración histórica, que como empresa intelectual quería ser un modelo de ordenación para los tiempos venideros.

\section{LAS ENCICLOPEDIAS}

Lo expuesto hasta aquí puede servir de marco adecuado para situar y comprender las enciclopedias y un género que, en ocasiones, me parece muy cercano a ellas, el de la consolación, tal como lo presentan Curtius o Courcelle, ${ }^{23}$ y tal como nosotros podemos configurar dicha tradición a través Boecio, Alfonso de la Torre ${ }^{24} \mathrm{o}$ en el mismo Alfonso de Toledo.

Las enciclopedias, desde el principio unificador cristiano que les ha ido envolviendo, marcarán una línea de continuidad y perfeccionamiento en la elaboración y preeminencia de lo religioso, que llegará hasta Alfonso de Toledo. Esta corriente y tradición, pasa entre otros, por Casiodoro, san Isidoro, Alano de Lille, Bartholomeus Anglicus (Bartolomé de Glanville), Alfonso de la Torre, Rodrigo Sánchez de Arévalo, o por el mismo Ramón Llull, y en muchos casos presentan contaminaciones del género de la consolación.

Las enciclopedias vienen a reflejar y condensar el momento cultural del que emergen y las tradiciones a las que pertenecen. Son el fruto de las distintas coyunturas y cosmovisiones históricas en su distinta tensión y plasticidad, en un esfuerzo de ordenación, sentido y

22 Ib. a. 8 .

23 Curtius, E.R., Literatura europea y Edad Media latina, FCE, México, 1984, I, 122. Courcelle, P., La consolation de philosophie dans la tradition littéraire. Antécedents et postérité de Boèce, Études Augustiniennes, París, 1967.

24 Fuertes Herreros, J. L. Sabiduría y' artes. 
gratificación. Sería limitado pensar que las enciclopedias son solamente un compendio de conocimientos clasificados según temas generales o según un método determinado. En ellas siempre nos aparece, al menos, por una parte el principio unificador que las sustenta y el sistema de relaciones que se establece entre las distintas ciencias y saberes, y por otra, la transmisión que se pretende hacer de dicha ordenación en base a su principio de unificación. Vienen a desempeñar una función teológico-ordenadora en la versión medieval de ellas.

Me refiero brevemente a algunas de ellas que tienen que ver con el propósito de nuestro trabajo.

\section{A) De Proprietatibus rerum, 1240, de Bartholomeus Anglicus}

Por los años en que enseñaba en París Bartholomeus Anglicus (Bartolomé de Glanville, 1220-30), el papa Gregorio IX enviaba la carta Ab Aegiptiis, ya comentada, y en 1240 terminaba su De proprietatibus rerum.

La obra de Bartholomeus Anglicus se me presenta, recogiendo el espíritu del XIII, como una mirada que desde lo divino ordena y contempla el conjunto de las realidades teniendo a Dios como principio y fin de todas las cosas. Comienza así la obra: «Deseando sacar a la luz algunas cosas acerca de las propiedades y naturaleza de las cosas tanto espirituales como corporales: arrancamos el proemio desde aquél; que es Alfa y Omega, principio y fin de todos los bienes. En el principio era la luz del Padre del cual procede todo lo mejor dado y todo don perfecto; implorando el auxilio para que aquél que ilumina a todo hombre que viene a este mundo; y revela las cosas profundas de las tinieblas; y las escondidas las lleva a la luz; a este opusculo -que a alabanza suya, y provecho de los lectores, ya comencé, no sin trabajo, a recoger con dichos diversos de santos y filósofos-, juzgue digno que feliz logre la terminación». ${ }^{25}$

Obra que tiene una finalidad bien concreta, tal como aparece en el proemio: «para la edificación de la casa del Señor: el cual es el Dios glorioso, sublime y bendito por los siglos de los siglos». ${ }^{26}$

Desde lo divino irá descendiendo hacia lo humano y terreno, dividiendo la obra en 19 libros: en el primero trata de Dios, en el segundo de los ángeles, en el tercero del alma, y así, sucesivamente: $4 .^{\circ}$ de la sustancia corporal, $5 .^{\circ}$ de la disposición de los miembros, $6 .^{\circ}$ de las edades, $7 .^{\circ}$ de las enfermedades, $8 .^{\circ}$ del mundo y de los cuerpos, $9 .^{\circ}$ del tiempo y de las partes de los tiempos, $100^{\circ}$ de la materia y de la forma, $11 .^{\circ}$ del aire y de las pasiones, $12 .^{\circ}$ de las aves, $13 .{ }^{\circ}$ del agua y de su adorno, $14 .^{\circ}$ de la tierra y su partes, $15 . .^{\circ}$ de las provincias, $16 .^{\circ}$ de las piedras preciosas, $17 .^{\circ}$ de los árboles y de las hierbas, $18 .^{\circ}$ de los animales, y, por último, $19^{\circ}$ de los colores, sabores y licores, en donde, además, hablará de las distintas clases de huevos y de los varios instrumentos musicales.

Concluye la obra con un explicit que condensa el espíritu que anima la enciclopedia y que está presente como finalidad en su autor: «Al mismo, honor y gloria, que es Alfa y

25 Bartholomeus Anglicus, De proprietatibus rerum, Nurembergum, 1519, «Incipit».

$26 I b$. , «Proemium». 
Omega; principio y fin de todos los bienes, que es el Dios sublime y glorioso que vive y reina por los siglos de los siglos. Amén». ${ }^{27}$

B) Visión deleytable de la philosofía et de las otras sciençias, 1430-40, de Alfonso de la Torre

Si he traído una enciclopedia del XIII ha sido para mostrar cómo hay una relación epocal y cultural en esa aspiración a la representación de un orden teológico en dicho siglo, y cómo esta pretensión parece ser el eje de vertebración de enciclopedias y de sistemas intelectuales que se van a ir sucediendo, así como de las instituciones transmisoras y cultivadoras del saber, esto es, las universidades a las que luego me referiré. Por otra parte, la enciclopedia de Bartholomeus Anglicus iba a ser muy conocida en el siglo XV con varias ediciones incunables.

Esto que acontecía en el XIII, de modo parecido quería acometerse en el XV. De ahí que las enciclopedias de comienzos del siglo XV no vayan a escapar a esa función teológicoordenadora, destacando entre ellas, y de modo admirable, la de Alfonso de la Torre. Visión deleytable de la philosofía et de las otras sciençias, 1430-40. Esta obra nos sitúa en un doble plano de realidad y de saberes: el mundano y el divino. Todos los saberes, como conocimientos engañosos, aparecen supeditados a la teología y a la revelación. Las artes del trivium y del quadrivium, así como la filosofía natural nos conducen en alegoría de ascenso al cielo, en donde se nos revela la verdad plena tanto en su vertiente teórica como práctica. ${ }^{28}$

Pero la enciclopedia de Alfonso de la Torre, a pesar de representar una función, también, teológico-ordenadora en la línea que venimos señalando, sin embargo, sabe recoger el espíritu renovador de las Constituciones que Benedicto XV y Martín V daban a la Universidad de Salamanca en 1411 y 1422 respectivamente, mostrando que una inflexión importante en la ordenación de los saberes se estaba dando en estos nuevos tiempos del siglo XV.

La obra de Alfonso de la Torre, que muy probablemente surge al calor de la Universidad de Salamanca en torno a 1430-40, mostraba el nuevo espíritu que la animaba, al igual que por estas fechas estaba sucediendo en otras universidades, en concreto, en la de París.

Las Constituciones de Benedicto XIII suponían el deseo expreso de impulsar el desarrollo intelectual y universitario en Castilla y de situar a la Universidad de Salamanca en la onda renovadora que desde la corte papal de Aviñón el papado había estado efectuando sobre la Universidad de París y sobre otros centros europeos. Se trataba de señalar los campos de lo humano y de lo específico religioso como realidades distintas, como Urbano V había propuesto en su reforma de la Universidad de París en 1366, al ofrecer una estructuración renacentista de los saberes en cuanto a la revalorización y consideración atenta de la facultad de Artes, o si se prefiere, en cuanto a la aceptación y exaltación de las realidades mundanas, para desde ahí vertebrar la Universidad.

27 Ib., fol. último.

28 Fuertes Herreros, 20-24. 
Las Constituciones de Martín V, en esta misma línea, insistían en la aceptación y reconocimiento de lo humano, señalaban la grandeza del conocimiento humano como condición primera para producir como culminación robustísimos púgiles y atletas en la fe católica. ${ }^{29}$ Se reforzaba lo humano como medio de exaltar más lo divino.

A la par que esta renovación constitucional en el centro salmantino, se va a producir, también, una renovación estatutaria, que culmina en el año 1439, en torno a los estatutos de Gramática y que significan una revalorizaci6n expresa de la facultad de Artes. Ésta, ahora, viene a encarnar el encuentro con el hombre, con la razón humana; tiene un ámbito específico y autónomo sin cuya atención, cultivo y desarrollo no sería posible cimentar otros saberes, ni establecer un diálogo múndano entre los hombres, y por supuesto, no sería posible obtener adecuadamente para la fe esos robustissimos pugiles et athletas.

Revalorización, en efecto, subsidiaria de lo religioso, y revalorización que es interpretada como signo de los tiempos y como tarea ineludible, pero que no altera el espíritu tradicional del obsequium rationale.

Es posible que, en el trasfondo de estas actitudes y en este acoger los nuevos signos de los tiempos, lata un esfuerzo por reorientar el nominalismo, que como mentalidad nueva desde la Universidad de París se había ido irradiando a toda Europa. En efecto, tras la Reformatio de la Universidad de París en 1366 de Urbano V, el nominalismo se fue irradiando de París y Oxford y se extendería rápidamente a todas las universidades europeas: a Viena, 1383, Heidelberg, 1386, Erfurt, 1392, Cracovia, 1397, Friburgo de Brisgovia, Basilea... Salamanca... y luego Alcalá..., configurando los rasgos de una nueva mentalidad, o un movimiento filosófico, humanístico y científico que iría manifestando y vertebrando en las universidades, y también fuera de ellas, a través de la ordenación de los saberes y de los curricula.

Y entre otros aspectos importantes, el nominalisme tenderá a una revalorización de la razón, a reclamar su autonomía frente a posibles supeditaciones. La armonía entre fe y razón, tan bien articulada en el tomismo, dará paso a la teoría de la doble verdad, filosófica y teológica, delimitando espacios y saberes, al surgimiento de todo un movimiento empírico-positivo que va a velar por todo aquello que suponga captación y expresión de la realidad por parte del hombre. Se empeñará en efectuar un tránsito de la metafísica a la lógica, a la gramática, a la filología y a la psicología, al vaciar de valor objetivo los conceptos universales y considerarlos como conceptus mentis. Y en el campo de la teoría política se irá manifestando por una fundamentación del poder político desde la razón, por la búsqueda de alternativas democráticas y el reconocimiento de la soberanía popular.

En el fondo, el nominalismo ponía en cuestión la bien trabada ordenación que se había elaborado desde un modo de entender el obsequium rationale, y por eso había, ahora, que

29 Benedicto XIII y Martín V, Constituciones, «preámbulos» de dichas constituciones: «Tandemque producit in fidei catholicae robustissimos pugiles et athletas», en Beltrán de Heredia, V. Bulario de la Universidad de Salamanca (1219-1549). Salamanca, 1966-67, II, 24 y 117. Fuertes Herreros, J. L., Estatutos de la Universidad de Salamanca, 1529. Mandato de Fernán Pérez de Oliva, Rector, Salamanca, 1984. 
reorientarlo, había que reconducirlo, aunque para ello hubiera que exaltar lo humano. Eran los signos de los tiempos.

Estos aspectos que, entre otros, nos descubren los cambios profundos que se estaban operando en el siglo XV, nos sirven, también, para enmarcar la enciclopedia de Alfonso de la Torre y valorarla en relación con esta situación y para ir comprendiendo la ruptura de la enciclopedia de Alfonso de Toledo a la que vamos tendiendo.

La enciclopedia de Alfonso de la Torre es un esfuerzo de clarificación en torno al fin último del hombre «para el cual finalmente fue criado» y desde el cual trata de poner orden dentro de «la turbación del mundo, et ignorancia et abominación de las sciencias que es hallada en los tiempos modernos», ${ }^{30}$ ofreciendo una ordenación de los saberes acorde con dicho fin último. Desde esta perspectiva, como ya dije antes, queda la obra dividida en dos partes. En la primera, después de haber caído en un profundo sueño, y de ser llevado a un altísimo monte, van apareciendo, en alegoría mujeres, las distintas artes liberales del trivium, gramática, lógica y retórica, las del quadrivium, aritmética, geometria, música y astronomía. Las artes del trivium proporcionan conocimientos como inștrumentos para posibilitar el descubrimiento y ascenso a la verdad. Las del quadrivium aparecen como ofreciendo un saber más profundo acerca de la realidad, aunque pecando siempre de cierta exterioridad. Tras estas artes aparecen la filosofía natural y la metafísica, que conducen y preparan a nuestro conocimiento para estar en condiciones de recibir la verdad. Con ello se abre la segunda parte.

Ésta consiste en la revelación que la Sabiduría hace de la verdad y en la desvelación que de dicha verdad se hace, tanto desde una perspectiva teórica como práctica. Se hablará de la existencia de Dios, de la inmortalidad del alma, del fin último del hombre, de la providencia, de la fortuna, del orden del universo, de todo aquello que impide al hombre conocer la verdad y la certidumbre de las cosas. Y de una vertiente práctica se planteará la ordenación de la vida desde presupuestos teológicos y desde el fin último del hombre, y se propondrá la «fe catholica santa y verdadera» como necesaria para la salvación, concluyendo con recomendaciones sobre las formas y deberes sociales y sobre el comportamiento político.

Están presentes en Alfonso de la Torre, La consolación de la filosofía de Boecio, De artibus ac disciplinis liberalium litterarum de Casiodoro, De Nuptiis Philogia et Mercurii et de septem artibus liberalibus de Marciano Capella, Anticlaudianus de Alano de Lille, además de tradiciones tales como el arte de la memoria, tradición tórica, neoplatonismo, aristotelismo... y, por supuesto, el cristianismo.

Pero, quizá, lo más interesante para nosotros, desde la perspectiva de análisis que voy siguiendo sea: $1 .^{\circ}$, que esta ordenación del saber continúa estando sustentada en una arquitectura teológica, desde el obsequium rationale; $2 .^{\circ}$ que la sabiduría se identifica con la teología y con la revelación, y no con la verdad que puede ser elaborada desde la razón

30 Alfonso de la Torre, Visión deleytable de la philosofía et de las otras sciençias, Tolosa, 1489, «Proemio». 
del hombre; $3 .^{\circ}$, que las artes y la filosofía, a pesar de su revalorización, dejan de ser expresión de la verdad del hombre y del mundo para convertirse en instrumentos que sirven para desvelar la verdad de Dios a través de lo creado.

\section{C) Speculum vitae humanae, 1468, de Rodrigo Sánchez de Arévalo}

Hacia 1468, quizá cuando Alfonso de Toledo estaba escribiendo su Invencionario, aparece en Roma el Speculum vitae humanae de Rodrigo Sánchez de Arévalo, obra que con repecto a la de Alfonso de Toledo nos muestra una nueva sintonía epocal con respecto a las artes, en concreto a las mecánicas.

Quizá los afanes por convertir a Roma, tras el cisma de Aviñón en la capital y en el centro de los nuevos tiempos que se inauguraban y de la nueva mentalidad que impulsaba, era la que iba a incidir en ese potenciar al máximo todas sus expresiones a través se los saberes, las artes y las disciplinas.

Será Nicolás V (1447-55) el que emprendería decididamente esta tarea, rodeándose de un grupo de hombres que encarnarán este espíritu, entre los que cabe señalar a Poggio, Filelfo y Lorenzo Valla, y se empeñaría también en su manifestación plástica a través de la reconstrucción de San Pedro, del Vaticano y de la misma Roma, iniciando además la transformación de la Biblioteca Vaticana, con especial interés por los manuscritos latinos y griegos.

De esta misma corte papal era de donde salía, en 1452, la nueva Reformatio de la Universidad de París del cardenal Estouteville: «Siendo recordados por nosotros desde la Sede Apostólica, y por Su Santidad, Señor Nuestro, Nicolás, por la divina providencia Papa $\mathrm{V}$, de cuya parte, aunque inmerecidos, hemos sido enviados», ${ }^{31}$ que potenciaba el espíritu de la Reformatio de 1366, indicando, ahora, que la reforma de Artes era pernecessaria. Será a este cardenal al que Arévalo dedicará su obra De castellanis et custodibus arcium.

Si la acción del papado se había empeñado con los nuevos tiempos, al menos en algunos aspectos, posibilitando su afloramiento y cultivo, es lógico pensar en su efecto irradiador a partir de esta década de 1450 y que en el resto de la cristiandad se tratase de imitar y difundir. Las universidades estaban ahora en condiciones de efectuar una profunda transformación y renovación de todos sus saberes, de emplear nuevas metodologías, de crear buenas bibliotecas, de cuestionar tradiciones y autoridades, de fomentar, en definitiva, la ciencia.

Esto va a procurar una elevación del status social de todos aquellos que se dedican al cultivo de las distintas artes, y no sólo de las tradicionalmente liberales. Se va a prestar especial atención a la arquitectura, pintura y escultura, y también a las artes prácticas como hilado, tintorería, alfarería, carpintería, ars mercandi et vendendi, y, sobre todo, a la minería y metalurgia, y lo que podríamos denominar genéricamente armatura.

En la Suma Política Sánchez de Arévalo recomendará que todo buen político debe «fazer que los cibdadanos se den a saberes y sciencias y actos studiosos» y que en «sus cibdades ayan estudiosos y famosos maestros, porque puedan aprender sciencias los

31 Denifle-Chatelain, Chartularium, IV. 714. 
cibdadanos y no sean ignorantes», que los ciudadanos «ayan continuo uso y exercicio en actos de ingenio y especulación y en actos studiosos, políticos y civiles». ${ }^{32}$

Ahora bien, la finalidad del Speculum vitae es pedagógico-moral.

En el prólogo señala que su obra está dirigida a los que tienen que orientarse en la vida y dudan sobre el camino a seguir, ${ }^{33}$ y quieren «recte eligendi ratio». Desde esta intención divide la obra en dos partes principales. En la primera trata de los diferentes estados o modos de vida temporales: emperadores, reyes, curiales, nobles militares, profesionales en artes mecánicas y liberales. Y en la segunda describe los diversos estados eclesiásticos: papa, cardenales, patriarcas, obispos, sacerdotes, religiosos, ermitaños. En ambas partes pretende señalar las ventajas e inconvenientes que se descubre en cada profesión o estado «para que el lector se dé cuenta de que, en cada estado y en cada profesión, en cada disciplina, encontramos tantas incomodidades y molestias, tantas virtudes y defectos que nunca se permanece contento y satisfecho». ${ }^{34}$

Divide Sánchez de Arévalo las artes en mecánicas y liberales, siguiento en lo esencial la ordenación de Hugo de San Víctor en el Didascalion. Las mecánicas aparecen divididas en: lanificium, armatura, navigatio, agricultura, venatio, theatrica, medicina. ${ }^{35} \mathrm{Y}$ las liberales, las del trivium, en gramática, dialéctica y retórica, y las del quadrivium, en música, geometría, aritmética y astronomía. ${ }^{36}$

Para Sánchez de Arévalo el conjunto de las artes mecánicas ha surgido para atender las necesidades y defectos corporales; y su finalidad es la de suplir los mismos defectos humanos: «La causa de la invención[...] fue el deseo de hacer frente a las necesidades y defectos corporales. Y el fin de ellos es el complemento de los defectos humanos». ${ }^{37}$ Y las distintas artes liberales a lo que deben tender, en ascenso, es a conocer principalmente al Creador y a alcanzar la vida eterna. En esto tiene, verdaderamente, que consistir su estudio y dedicación. ${ }^{38}$

La enciclopedia de Rodrigo Sánchez de Arévalo significa un paso importante en esa revalorización progresiva que se va dando en el XV de lo humano, de las artes mecánicas y de todo lo que representa acción del hombre, como respuesta ante las nuevas necesidades y realidades que se estaban planteando en una sociedad y en un mundo que no podía por menos que ser renacentista. Pero la solución última que propugna tiene un tono medieval, acaba habiendo una preeminencia de lo religioso, la unificación de la realidad se consigue ordenar desde lo transcendente, en esa tensión y en ese tender de lo humano a la llamada de Dios.

32 Sánchez de Arévalo. R., Suma de Política, BAE 116, Madrid, 1959, 260, 281.

33 Muñoz Delgado, V., «Las artes mecánicas y liberales en Rodrigo Sánchez de Arévalo», 37.

$34 \mathrm{Ib}$.

35 Sánchez de Arévalo, R. Speculum vitae, Roma, 1468, cap. 23-34.

36 Ib., cap. 35-40.

37 Ib., cap. 24. Muñoz Delgado, 44.

38 Ib., cap. 40: «Que se descubre que conocen las magnitudes y las cualidades extrínsecas [...]. Ves, hijo mío, que serán, de este modo, las artes matemáticas desplazadas por las artes y las ciencias de la piedad, las cuales conducen a la vida eterna, a la cual tienden a dirigirte todos mis estudios». Muñoz Delgado, 59. 


\section{EL INVENCIONARIO, 1474, DE ALFONSO DE TOLEDO}

\section{A) Descripción general de la obra}

El Invencionario desde la lectura de Génesis, 1-3, va a partir de ese hombre que nos había dejado en situación de necesidad y que mediante el benefiçio de la razón se va a ver forzado a iniciar la historia como tiempo de invenciones, como espacio en el cual ejercitar el ars inventiva. El hombre mediante la razón y el ars inventiva conseguirá la salvación, esto es, por una parte, atenderá y suplirá sus necesidades y defectos corporales, tal y como también apuntaba Sánchez de Arévalo o tal como aparecía en la tradición clásica, entre otros, en Aristóteles, Plinio, Plutarco, Lucrecio, o en el mismo Sto. Tomás, o tal como luego se hará eco Montaigne en sus Ensayos; y por otra, como medio de alcanzar la vida eterna. Invenciones, que surgen del hombre, y que están ajustadas a cada uno de los fines que desde su empeño dicho hombre ha ido persiguiendo a través del tiempo histórico.

Desde esta perspectiva, en este hacer la historia de las invenciones y de señalar aquellas invenciones e inventores que considera más significativos, va a recoger diversos materiales de distintos autores y tradiciones. Destaca la tradición enciclopédica, y de modo especial S. Isidoro y sus Etimologías, que será la obra más citada tanto dentro de esta tradición como dentro del conjunto, Ricardo y Hugo de San Víctor, Bartholomeus Anglicus y Boecio. Dentro de la tradición histórico-eclesiástica destacan Pedro Comestor (o Manducator) y su Historia scholastica, Tolomeo de Lucca (de Fiadoni) y su Historia ecclesiastica y Casiodoro con su Historia Ecclesiastica vocata Tripartita. Dentro de la tradición jurídico-canónica, Graciano, Pedro Lombardo, Bártulo de Saxoferrato, Juan Andrés, Rábano Mauro y Guillermo Durant, entre otros. La Sagrada Escritura será otro de los puntos de referencia, así como algunos padres de la tradición patrística como S. Agustín, S. Juan Crisóstomo y S. Ambrosio. También la tradición clásica, entre ellos, Homero, Platón, Pitágoras, Epicuro, Virgilio, Cicerón, Salustio y Varrón.

Dividirá la obra en dos partes principales.

La primera la dedicará a «declarar los ynventores de las cosas que los omes ynventaron para la sustentación de la vida temporal». ${ }^{39}$ De acuerdo a esa solución de necesidades dividirá el libro primero o la primera parte en diez títulos: el primero lo dedicará a las letras y sus inventores; el segundo, a los reinos y a sus inventores; el tercero, a la leyes y sus inventores; el cuarto, a los inventores de las ciudades; el quinto, al casamiento y sus excelencias; el sexto, a los inventores del pan y a los inventores de los instrumentos de labranza, también del vino y de la carne; el séptimo, a los inventores de las cosas necesarias para el vestir; el octavo, a los inventores de las armas y de los metales, de la fabricación de ellas, y de los caballos, de las batallas, de los pendones y de las insignias; el noveno, a los inventores de algunas artes que los hombres inventaron para «aver deporte e aliviar trabajos»; y el décimo, a la invención de la medicina y astrología y otras artes. 
Toda esta primera relación de invenciones para el mejoramiento y «sustentación de la vida temporal» las va a situar en el tiempo de la historia, fijando cada una de ellas en el tiempo en que fueron inventadas. Siguiendo a San Isidoro, dividirá el tiempo de la historia en siete edades, añadiendo una más a las seis del santo: la séptima que irá del juicio hasta el sin fin. ${ }^{+0}$ Tradición que culminará, entre otros, en el siglo XVII con Petavius Dionysius, 1583-1652, y su Opus de doctrina temporum o su Rationarium temporum, hasta que quiera ser sustituida por Kant al plantear la construcción de la historia como sistema de la razón.

La segunda parte tratará de «los ynventores de las cosas que los omes ynventaron para adquirir la vida eternal», ${ }^{+1}$ o más explícitamente: «de los ynventores de las cosas de que los omes usaron y usan para aplaser a nuestro Señor y recobrar aquella gloria y beatífica morada que los padres primeros por su culpa perder meresçieron».+2 Y justificará este punto de partida con diez consideraciones: «Ca me paresçió que todos los inventores de las cosas con que los omes pensaron aplaser a Dios se pusieron mover e movieron dies consyderaçiones. Ca unos buscaron remedios para la mansilla del pecado original, e los otros pensaron aplaser a Dios por fe, los otros por oración, los otros por limosnas, los otros con ayunos, los otros con sacrificios, los otros con celelebraçión de fiestas, los otros por martirios e religión, los otros dedicando e hedificando templos en honor e reverençia suya, los otros por penitencia». ${ }^{13}$ Consideraciones que le permitirán, a su vez, dividir esta segunda parte en otros diez títulos: el primero que tratará de los inventores contra el pecado original; el segundo, de los inventores de la fe; el tercero, de los inventores de la oración; el cuarto, de los inventores de la limosna, diezmos y primicias, y oblaciones; el quinto, de los inventores del ayuno; el sexto, de los inventores de los sacrificios y primeros sacrificios en las tres leyes; el séptimo, de los inventores de la celebración de las fiestas; el octavo, de los primeros mártires y religiosos; el noveno, de los inventores de altares, templos e iglesias sagradas; y el décimo, y último, de los primeros inventores de la penitencia. ${ }^{+4}$

Cada uno de estos títulos los va a exponer desde una triple perspectiva, desarrollándolos en el marco de una historia que se halla dividida en tres leyes: ley de natura, ley de escritura y ley de gracia. Esta triple división le servirá para fijar cada invención y a cada inventor en el tiempo de esa historia. La ley de natura comenzó con Adán, la de escritura con Moisés, y la de gracia «en el año quinseno del imperio de Tiberio a treinta años de la Natividat del Salvador»; ${ }^{45}$ recogiendo esta tradición, entre otros, de la Decretal, de Ricardo de San Víctor y de Tolomeo de Lucca. Sin embargo, esto que podía parecer una historia religiosa o un situarse en una historia de la salvación, no es así. Parece más bien, que el marco de esta

40 Fol. 10b.

41 Fol. 8v/a.

42 Fol. 47a-47b: «En la qual tratar prometo de los ynventores de las cosas de que los omes usaron y usan para aplaser a nuestro señor y recobrar aquella gloria y beatífica morada que los padres primeros por su culpa perder meresçieron».

43 Fol. 47v/a.

44 Fol. 48a-112v/a.

45 Fol. 48a. 
historia, así dividida en leyes, es la que mejor se ajusta para la exposición que pretende de esta clase de invenciones. Del hecho de estar en la ley de gracia, Alfonso de Toledo no saca las consecuencias ni las derivaciones pedagógico-morales que hubiera cabido esperar.

\section{B) El orden del saber en el Invencionario}

Una mirada atenta sobre el Invencionario nos descubre cómo éste esconde un orden o una arquitectura del saber tras esa historia de las invenciones, que se ajustaba a esa situación histórica de la segunda mitad del siglo $\mathrm{XV}$, apostando por una nueva ordenación y consideración de lo humano, y también de lo religioso. Veámoslo en cada una de sus partes.

En la primera parte están recogidas todas las artes mecánicas, que aparecían en Hugo de San Víctor y en Sánchez de Arévalo, además de las liberales del trivium y del quadrivium que Alfonso de Toledo sabe compendiarlas en la medicina. Así mismo están presentes casi todos los grandes temas de las Etimologías de San Isidoro, más todo un conjunto de cuestiones que venían de la ciencia política y del derecho, títulos $2 .^{\circ}$ y $3 .^{\circ}$. Con estos elementos Alfonso de Toledo nos va a ir descubriendo, desde ese tender a la «sustentaçión de la vida temporal», en primer lugar, cómo se puede o se ha ido posibilitando la vida, y en segundo lugar, cómo se puede o se ha ido posibilitando la convivencia y el desarrollo del hombre.

De esta manera, todas las artes y saberes entran en relación. Las artes mecánicas y las artes liberales, que se compendian como punto culminante en la medicina, tienden a esa posibilitación de la vida. Y los títulos segundo y tercero, que tratan respectivamente de los inventores de los reinos y de los primeros reyes y grandes señores, así como de los inventores de las leyes y derechos, y de la división de ellos nos ofrecen los elementos a través de los cuales se puede posibilitar la convivencia y el desarrollo del hombre.

Veamos cómo a través de las distintas invenciones Alfonso de Toledo sabe recoger las artes mecánicas y prepararlas para una nueva finalidad y consideración, según la división de Hugo de San Víctor que recogía Sánchez de Arévalo. ${ }^{46}$

El lanificium, que comprendía el arte de tejer, hilar, coser, los oficios que empleaban la aguja, el uso, la rueda o instrumentos semejantes, las pieles, pelo o seda. Este arte que tendía a proteger la vida del cuerpo va a ser desarrollado por Alfonso de Toledo en el título séptimo: «de los primeros ynventores del vestir». ${ }^{+7}$

La armatura, que incluía los oficios en que se trabajaba con hierro, metales madera, la acuñación de moneda, fabricación de carruajes, escultura; alquimia. Admitía dos divisiones principales, la fabrilis, que entre otros cometidos tenía la fabricación de armas, y la arquitectonica, que se dividía a su vez en carpentaria y cementaria. Nuestro autor la tratará, pricipalmente, en el título octavo: «de los ynventores de las armas». ${ }^{48}$

46 En la descripción de cada una de las artes mecánicas de Hugo de San Víctor sigo la que hace Muñoz Delgado, 44-49.

47 Fol. 30v/a-32a.

48 Fol. 32a-43v/a. 
La navigatio, el ars mercandi et vendendi, comprendía todo lo relativo a la venta, compra y cambio de mercancias. Uno de sus instrumentos principales era la navegación. Si la navegación no aparece específicamente en el Invencionario, sí que lo hace «la ynvençión del contrato del comprar e vender» en el título sexto, capítulo doce. ${ }^{49}$

El ars venatoria, que englobaba la pesca y caza en tierra, mar, ríos y aire, la preparación de comidas y bebidas, y en general, todos los oficios de los pescadores, cazadores, carniceros y taberneros. Y la agricultura, que incluía todo lo relacionado con la tierra, bosques, pastos y huertos. Ambos van a ser recogidas, junto con el ars pastorilis, que oscilaba entre el ars venatoria y la agricultura, en el título sexto: «de los primeros ynventores del pan e de los instrumentos con se labra e de los primeros ynventores del vino e de la carne».50

El ars theatrica se refería a los juegos públicos y privados, los oficios de los comediantes, trágicos, torneos, justas, juegos de azar, corridas de toros, bufonería, histrionismo y de todo aquello que podía ayudar a «deleyte de natura humana». Este aspecto aparece en el título noveno, que habla de los «ynventores de algunas artes que los omes ynventaron por aver deporte e aliviar trabajos», ${ }^{51}$ pero ampliando los temas del ars theatrica e introduciendo otros ajenos a este arte y que mira más bien a la «aliviación» del trabajo, tal como eran los «ynventores del domar de las bestias», «de la ynvençión del linaje de mulos», o de los «ynventores de carros y carretas», temas que por otra parte aparecían en S. Isidoro, ${ }^{52}$ aunque no con esta idea expresa de «aliviación» del trabajo.

Este conjunto de invenciones y de inventores, que Alfonso de Toledo presenta, en torno a esos núcleos de las artes mecánicas y que miran a posibilitar la vida, se va a ver completado por la nueva orientación que nuestro autor va a dar a las artes liberales del trivilum y del quadrivium.

Éstas, ahora, no van a estar al servicio ni de la filosofía ni de la teología, sino de la medicina, o mejor, todas las artes «se contienen so la medesçina», ${ }^{53}$ pues «poco aprovecharía a los humanos aver sabido ynventar todas las cosas de susso notadas para la sustentaçión de la vida temporal si non se pudiesen ayudar por scientia como fuessen sanos de enfermedades que por natura o por acçidente les ocurren». ${ }^{5+}$

Dentro de la medicina quedan incluidas también la astronomía y la astrología, la cual dice que en parte es natural y en parte supersticiosa, $\mathrm{y}$ «de la qual los médicos en muchos cosas le ayudan», 55 "por la qual contemple la razón de las estrellas e la mudança de los tiempos, ca con la calidat de los cuerpos sobreçelestiales, nuestros cuerpos resçiben mudança». ${ }^{56}$ Lo mismo le acontece a la filosofía con respecto a la medicina: «anexo es el

49 Fol. 29v/b-30v/a.

50 Fol. 26a-29v/b.

51 Fol. 40v/a-47a.

52 Etimologias, XII,1; XX,12.

53 Fol. 46v/a.

54 Fol. $43 v / a-43 v / b$.

55 Fol. 44b.

56 Fol. 46v/a. 
buen médico ser filósofo», «e por tanto la medesçina segunda philosofía es dicho, e por eso dixe susso a la medesçina mucho ser neçesaria la çiençia de la philosofía». ${ }^{57} \mathrm{Y}$, aunque pudiera que estar tomado de las Etimologías de San Isidoro, dice: «De aquí que se considere a la medicina coma una segunda filosofía. Una y otra ciencia reclaman para sí al hombre entero; pues si por una se sana el alma, por la otra se cura el cuerpo». ${ }^{58} \mathrm{Sin}$ embargo, queda claro que Alfonso de Toledo no es que eleve al mismo rango la filosofía y la medicina, sino que la filosofía queda comprendida en y al servicio de la medicina.

Ahora bien, si estas artes son necesarias para posibilitar la vida, tratando de superar aquella situación de necesidad en la que el hombre se vio sumido o en la «que natura de suyo administra a los brutos animales las cossas nesçessarias a la sustentaçión de su vida, las quales niega a la espeçie humana», ${ }^{59}$ y una vez cubierta, de lo que se trata es de ordenar la vida de los hombres. Como invenciones importantísimas en esta ordenación señala cuatro:

1. ${ }^{\text {a }} \quad$ La «de las letras y fyguras dellas. E de los modos diverssos de escrivir y de los pergaminos y materia en que escrivimos», a la que dedica el título primero. ${ }^{60}$

2. ${ }^{a} \quad$ La que figura en el título segundo: «de los primeros ynventores de los regnos e de los primeros reyes e grandes señores». ${ }^{61}$ Cabe destacar que, en contra de los planteamientos y de las apelaciones de Santo Tomás en torno al fin último del hombre para fundamentar la política y derivarla de una concepción religiosopastoral, tal como aparece en La monarquía (De regno), Alfonso de Toledo la va a fundamentar en el acuerdo, en ese acuerdo que es dictado por la razón para salir del estado de confusión, discordia y disensión en el cual el hombre, al llegar a ser muchedumbre, se veía inmerso. ${ }^{62}$ De este fundamento contractualista y su cumplimiento se servirá para rechazar la tiranía.

3. ${ }^{2} \quad$ La tercera invención encaminada a posibilitar la convivencia de la mano del título tercero dedicado a los «ynventores de las leyes e derechos e de la dyvissión e partimento dellos», con derivaciones a cuestiones prácticas como tormentos, cárceles y prisiones, los testigos en los pleitos o la «ynquisiçión o pesquisa». ${ }^{63}$

4. ${ }^{\mathrm{a}} \quad$ Y como última invención señala el matrimonio, al que dedica el título quinto, y «que para la paçifica bivienda de las gentes mucho nesçessario fue». ${ }^{6+} \mathrm{La}$ defensa y excelencias del matrimonio que hace, así como el ataque que efectuará al

57 Fol. 45v/a; 46v/a.

58 Etimologías, IV, 13, pág. 507.

59 Fol. 13a-13b. Cf. fol. 8v/b donde señala: «Cierto es [...] a los brutos animales administra».

60 Fol. 10b-13a.

61 Fol. 13a-15a.

62 Fol. 13b: «E como estos non se podían administrar salvo por muchedumbre de omes los quales por esta causa ovieron nesçesario venir ayuntadamente. E por que toda muchedumbre era materia o causa de confusión, discordia e disenssión, acordaron de señorear sobre sy uno que sus disenssiones e discordias con ygualdat concordasse e a esto pussyeron nombre rrey, que quiere dezir regidor o regiente».

63 Fol. 15a-18a.

64 Fol. 21v/b-26b; 22a. 
celibato de los clérigos, ${ }^{65}$ es una pista deliciosa para poder hablar de la modernidad de Alfonso de Toledo y para señalar los nuevos ojos con que en el Renacimiento se veía el matrimonio o la vida mundana. Actitud muy distante de como aparecía en Alfonso de la Torre en su Visión deleytable o en la Theologia naturalis seul liber creaturarum de Ramón Sibiuda (m. 1436), por no mencionar a san Isidoro.

De esta manera y con esta ordenación del saber, se cierra la primera parte. Los saberes y las invenciones tienen una finalidad no trascendente, ni subsidiaria, sino inmanente y concreta: el hombre, su mejoramiento, su gratificación. Y este hombre es el que aparece como artifex, como creador de toda esa generación de invenciones, es el creador de un nuevo relato del Génesis, que tiene su origen en la propia necesidad del hombre. Y este relato lo proyecta en el tiempo de una historia que es un ejercitar la razón, buscando el mejoramiento y perfección del hombre, dotándolo de todo aquello que la naturaleza le negó.

Esta ordenación significa romper ese nivel de subsidiaridad en que habían quedado los productos de la razón del hombre. La quiebra del obsequium rationale está ahí presente. La razón queda constituida en señora de los saberes, de los espacios de lo finito y de la naturaleza a la que tiene que someter para el hombre. Los saberes y las artes mecánicas ya no están al servicio de un saber trascendente, la teología o la revelación. Son todos igual de nobles por provenir de la razón del hombre y por concurrir todos a la par al mejoramiento de éste. La medicina es, ahora, la ciencia que compendia todas las ciencias, incluida la filosofía.

\section{C) Lo religioso en el Invencionario}

La segunda parte del Invencionario está dedicada a los «ynventores de las cosas que los omes ynventaron para adquirir la vida eternal». En ella trata de los «ynventores de las cosas de que los omes usaron y usan para aplaser a nuestro Señor y recobrar aquella gloria y beatífica morada que los padres primeros por su culpa perder meresçieron». ${ }^{66} \mathrm{Y}$ ésta es la perspectiva y el punto de partida con que nos encontramos al plantear lo religioso y la religión en Alfonso de Toledo. La religión aparece, también, surgiendo del hombre y como un conjunto de invenciones o prácticas religiosas con las cuales aplaser a Dios. De Dios poco más sabemos, aparte de ser el creador del hombre y de estar ayrado con éste.

Esto me hace sospechar que en el Invencionario se halla rota y fragmentada aquella arquitectura y ordenación que en base al obsequium rationale propiciaba, o bien una mirada desde lo divino, descendiendo hacia las criaturas y realidades terrenas, según el modelo de Bartholomeus Anglicus en su De propietatibus rerum, o bien ese ir ascendiendo hacia lo divino, desde una opción previa de fe, para que se nos ofreciera la revelación de la verdad y acabáramos viendo toda la realidad, también, desde lo divino, tal como aparecía en el modelo de Alfonso de la Torre o en el mismo Sto. Tomás.

65 Fol. $91 \mathrm{v} / \mathrm{b}-92 \mathrm{a}$. A esto hay que añadir el cúmulo de detalles y el relato colorista con que narra el caso de la papisa, Juan VIII, fol. 86v/b-87a.

66 Fol. 47a-47b; 8b-8v/a. En el primer caso aplaser y en el segundo aplazer. 
Ninguna de estas soluciones o tradiciones parece que sean viables desde la perspectiva de Alfonso de Toledo. Se nos ha fragmentado esa posible articulación y unificación, que lo teológico y una visión teológica propiciaban. La nueva unificación que propugna el Invencionario viene de la mano de la razón, y ésta ocupa los espacios que antes habían sido reservados a la teología y a Dios. La razón es el nuevo principio unificador y creador. Y creador, inclusive, frente a Dios.

Ya indiqué que el relato del Génesis, 1-3, de Alfonso de Toledo carecía de esa promesa de salvación que, en definitiva, era la que servía para establecer esa relación paterno-filial entre Dios y los hombres. Y que era, por otra parte, la que cabría esperar en buena medida de un bachiller en Decretos del XV.

Ahora bien, Alfonso de Toledo confiesa, refiriéndose al cometido de esta segunda parte: «E la materia de la qual, como toda ella sea de los teólogos y yo de la Teología muy poca tengo po olvidar, non me debe culpar vuestra muy reverenda paternidad, sy las materias por mi tocadas, mal explicadas dexare». ${ }^{67}$ Lo cual podía servir para encubrir su «atrevimiento» más que su falta de formación teológica. Y esto lo señalo, ya que a continuación introduce esa cláusula de seguridad, tan querida y socorrida para diversos fines en esta época: «E protesto sy en este mal compuesto libello algo dixere digno de rephensión, que lo he por non dicho. Antes digo, confieso y afirmo todo aquello que la Santa Yglesia de Roma dise, confiesa y afirma, y non más, nin allende». ${ }^{68}$

Esta ausencia de una promesa de salvación y esa falta de una relación paterno-filial entre Dios y los hombres, es lo que posibilita al autor del Invencionario presentar la religión y lo religioso como ese conjunto de invenciones, tornadas en prácticas para aplaser a Dios y recobrar la gloria y beatífica morada. Dios no sabemos ahora dónde ha sido confinado, ni resulta fácil decir algo de él. ¿Será esto la fe? Pues, como decía san Isidoro al que cita, la fe «es aquella cosa por la qual verdaderamente creemos lo que por alguna manera ver non podemos». ${ }^{69}$

Inventos y prácticas que se han sucedido variando en el tiempo, ceñidos a las tres leyes: la de natura, escritura y gracia. Pero leyes que siempre han tenido la misma fe: «esta fe es estos tres tiempos quanto a la sustancia non fue diversa más una y esta misma. E la nuestra fe con la fe de los antiguos una essa misma es en sustancia [...] ca ellos creyan Xristo aver de venir y nos creemos ser venido. Esta diversidad sólo es en el tiempo». ${ }^{70}$

Fe que, por otra parte, parece creer en un Dios lejano y distante al que hay que aplaser, efecto que con las diversas invenciones parece haberse conseguido. Remedios para el pecado original, inventores de la fe, de la oración, primicias, décimas y oblaciones, ayunos, sacerdotes, sacrificos, fiestas, mártires, altares, templos, iglesias, penitencia. Todo parece haber intentado la razón, el hombre.

67 Fol. 47b.

68 Fol. $47 \mathrm{~b}$.

69 Fol. 153v/a. Etimologías, VIII, 2,4, pág. 365.

70 Fol. 54v/a. 
No asistimos a ninguna revelación en el Invencionario por parte de la Sabiduría ni por parte de la divinidad, ni se nos desvelan los grandes misterios de Dios o de Cristo, o de la Iglesia, ni se nos habla de la teología, ni nuestro tiempo finito parece surgir o desgajarse del infinito. Todo, por el contrario, parece emerger del hombre que ritualiza su relación con Dios en espera de alcanzar esa gloria y beatífica morada.

Si a esto añadimos las críticas a la Escritura, la búsqueda de posibles contradicciones, ${ }^{71}$ la ridiculización de algunas imágenes de Dios, ${ }^{72}$ su oposición a la representación de Dios en imágenes ${ }^{73}$ las críticas a la Iglesia, en concreto el celibato, ${ }^{74}$ percibimos cómo Alfonso de Toledo representa una ruptura con el mundo medieval y que a esta altura de 1474 hemos entrado en la época moderna. Quizá el obsequium rationale ha sido sustituido por esa andadura que se inicia, y que se va a empeñar en construir una scientia rationalis desde el nuevo relato creador que se abre ahora. Relato creador en el cual la razón asumirá el papel de Dios e impondrá, desde la seguridad moderna, nombre a las cosas. Por su parte, la religión desplazada de ese relato ordenador, se verá obligada a actuar como referente desde el cual se pueda sospechar de las seguridades de la razón.

\section{CONCLUSIÓN}

He intentado asomarme a la obra de Alfonso de Toledo y desvelar algunos de su significados más notables. Ello me ha conducido a acercarme a la Edad Media y a señalar algunos de sus elementos nucleares y tradiciones, entre las cuales aparece la de las enciclopedias del saber. Esta necesaria vuelta al mundo medieval surge aquí con toda su fuerza.

El Invencionario nos ha situado en ese declinar de la Edad Media al Renacimiento, buscando un nuevo principio de ordenación y de unificación de los saberes y de las invenciones en la razón del hombre, reorientando el saber enciclopédico y las enciclopedias, que se irá consolidando a través del Barroco y de la Ilustración.

Por otra parte, la enciclopedia de Alfonso de Toledo no sólo nos ha ejemplificado una ruptura con respecto a la ordenación del saber, sino que nos anuncia lo que van a ser algunos de los intentos que se van a ir sucediendo en la modernidad y que van a ir configurando la tradición enciclopédica, llegando, en modos diversos, hasta nosotros.

José Luis Fuertes Herreros

Depto. de Filosofía

Facultad de Filosofía

Campus Miguel Unamuno

E-37006 Salamanca

71 Fol. 26/b; 28v/b-29/a; 30/a-30v/a; 32v/b-33/b.

72 Fol. 30v/a-30v/b.

73 Fol. 69v/a.

74 Fol. 91v/b-92/a. 